\title{
Plasma Ephrin-A1 level in a cohort of diabetic retinopathy patients
}

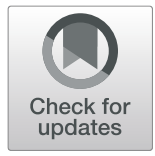

\author{
Danna Mao', Ying Hu', Qi Bao², Kewei Wu', Yaoding Zheng' ${ }^{1}$ Yukun Yang ${ }^{1}$, Bo Lei ${ }^{3^{*}}$ and Ying Jiang ${ }^{1 *}$
}

\begin{abstract}
Background: To determine plasma ephrin-A1 and VEGF ${ }_{165}$ levels in a cohort of diabetic retinopathy patients.

Methods: Plasma ephrin-A1 and VEGF 165 levels in fifty-five subjects including 19 individuals without diabetes (nonDM), 16 patients with diabetes (DM) but without diabetic retinopathy, and 20 patients with diabetic retinopathy (DR), were determined by ELISA. Serum creatinine, total cholesterol, fasting blood glucose and HbA1c were also measured. One-way ANOVA, Kruskal-Wallis Test, Mann-Whitney U Test corrected by Bonferroni, Pearson Correlation Analysis and Spearman Correlation Coefficient Analysis were used for data analysis.

Results: Ephrin-A1 expression could be detected in human plasma with an average of $1.52 \pm 0.43$ (mean \pm SEM) $\mathrm{ng} / \mathrm{ml}$. In DR subjects, the plasma ephrin-A1 concentration was $3.63 \pm 4.63 \mathrm{ng} / \mathrm{ml}$, which was significantly higher than that of the other two groups (non-DM: $0.27 \pm 0.13 \mathrm{ng} / \mathrm{ml}$, DM: $0.35 \pm 0.34 \mathrm{ng} / \mathrm{ml}$ ). The expression of VEGF 165 in human plasma was $34.00 \pm 42.55 \mathrm{pg} / \mathrm{ml}$, with no statistical difference among the three groups. There was no correlation between ephrin-A1 and VEGF 165 in human plasma, but there was a correlation between plasma ephrinA1 and duration of diabetes.

Conclusions: Plasma ephrin-A1 was highly expressed in patients with diabetic retinopathy, and there was no difference of plasma VEGF 165 expression in patients with diabetic retinopathy compared to the other two groups, suggesting that changes of plasma ephrin-A1 may be a more sensitive biomarker than plasma VEGF 165 in detecting diabetic retinopathy.
\end{abstract}

Keywords: Ephrin-A1, VEGF 165 , Plasma, Diabetic retinopathy, ELISA

\section{Background}

It is estimated that there are 382 million diabetic patients worldwide, and about one third of these patients have diabetic retinopathy (DR), part of them have diabetic macular edema. DR causes visual impairment in about 37 million people around the world [1]. About $60 \%$ of type 2 diabetes patients present DR of varying degrees 20 years after being diagnosed with diabetes. DR is induced by hyperglycemia,

\footnotetext{
*Correspondence: bolei99@126.com; gateways@126.com

3People's Hospital of Zhengzhou University, Henan Provincial People's Hospital, Henan Eye Institute, Henan Eye Institute, 7\# Weiwu Road,

Zhengzhou 450003, Henan, China

'Department of Ophthalmology, Medical community of Fenghua Hospital of Traditional Chinese Medicine, 22 Zhong Shan Road, Feng Hua District, NingBo 315500, ZheJiang, China

Full list of author information is available at the end of the article
}

which leads to retinal vascular endothelial injury, retinal vascular loss, ischemia, and changes of leukocyte adhesion $[2,3]$. Consequently, production of precursor substances of various angiogenic factors and inflammatory cytokines increased which induced abnormal neovascularization [4] and microvascular dysfunction.

In the pathogenesis process of DR, endothelial-derived growth factor (VEGF) is a major cytokine that promotes neovascularization, which leads the destruction of blood retinal barrier and indirectly promoting the progress of DR. Several spliced isoforms of VEGF present in human body with 121, 145, 165, 183,189, and 206 amino acids in length [5]. VEGF 165 appears to be the most abundant and potent isoform in inducing neovascularization, followed by $\mathrm{VEGF}_{121}$ and $\mathrm{VEGF}_{189}[5,6]$. In vivo and

C The Author(s). 2020 Open Access This article is licensed under a Creative Commons Attribution 4.0 International License, which permits use, sharing, adaptation, distribution and reproduction in any medium or format, as long as you give appropriate credit to the original author(s) and the source, provide a link to the Creative Commons licence, and indicate if changes were made. The images or other third party material in this article are included in the article's Creative Commons licence, unless indicated otherwise in a credit line to the material. If material is not included in the article's Creative Commons licence and your intended use is not permitted by statutory regulation or exceeds the permitted use, you will need to obtain permission directly from the copyright holder. To view a copy of this licence, visit http://creativecommons.org/licenses/by/4.0/. The Creative Commons Public Domain Dedication waiver (http://creativecommons.org/publicdomain/zero/1.0/) applies to the data made available in this article, unless otherwise stated in a credit line to the data. 
in vitro experiments have shown that ischemia and hypoxia induces VEGF expression, which causes retinal neovascularization [7]. In addition, it has been shown that VEGF levels in the vitreous of DR patients were higher than those in the control group [8]. Intravitreal injection of anti-VEGF drugs has a certain therapeutic effect on PDR patients $[9,10]$. However, there are disadvantages that anti-VEGF drugs require multiple intravitreal injections for the treatment of DR, that maybe causing preretinal tissue shrinkage and retinal detachment [11]. In addition, anti-VEGF drugs have adverse effects such a mild cerebrovascular accident and myocardial infarction. Therefore, it is necessary to find more appropriate approaches or new therapeutic targets.

Ephrins and the Eph receptors have been identified as key regulators of angiogenesis [12]. Class A Eph receptors have been shown to regulate postnatal angiogenesis in adults. Earlier studies have shown that ephrin-A1 stimulates the migration of cultured endothelial cells and induces corneal angiogenesis [13]. Expression of ephrin-A1 was found in the process of embryonic vascular development [12] and tumor growth [14]. These evidences indicate that ephrin-A1 plays an important role in angiogenesis. We became interested whether ephrin-A1 is expressed in human plasma, and whether the plasma ephrin-A1 expression was altered in diabetic retinopathy patients.

\section{Methods}

\section{Subjects}

This study was approved by institutional ethics committee in the Fenghua Hospital of Traditional Chinese Medicine. Informed consents in written format to publish these date were collected from each patient, who agreed and signed the consent to participate statement. Primary angle-closure suspect was inclusion criteria, because there were no reports about the association between ephrin-A1 and primary angle-closure suspect, or VEGF and primary angle-closure suspect in the literature. In addition, there is no vascular changes or cytokine changes that are associated with angiogenesis in primary angle-closure suspect. The recruited patients were enrolled between August 1, 2018 and October 31, 2019 with the following inclusion criteria:

(1) Over 40 years of age.

(2) Clinical diagnosis of primary angle-closure suspect, diabetes mellitus and DR.

(3) Patients agreed to provide informed consent.

The definition of primary angle-closure suspect was in accordance with the International Society of Geographical and Epidemiologic Ophthalmology criteria [15]. Diabetes mellitus was diagnosed according to the international standards [16]. Diagnosis of DR was made based on an international standard [17].

The subjects with any diseases that presented neovascularization such as kidney disease and cancer, or any of those subjects received anti-VEGF therapy or operations were excluded.

A total of fifty-five patients from Fenghua District were recruited. Nineteen patients with primary angle-closure but without diabetes were enrolled in the non-DM group. Sixteen patients with primary angle-closure and diabetes were enrolled in DM group. Twenty patients with DR were enrolled in DR group, about 35\% of patients with proliferative diabetic retinopathy.

After routine physical and eye examinations, electrocardiogram, clinical laboratory tests including liver and kidney function tests, routine ophthalmic examinations, fundus photograph and fluorescein angiography were performed.

The averaged duration time of type $2 \mathrm{DM}$ in the diabetic group was $46 \pm 18.5$ months. The averaged duration time of type $2 \mathrm{DM}$ with DR was $118 \pm 49$ months.

\section{Collection of blood samples}

The blood samples were collected using ethylenediaminetetraacetic acid (EDTA) as an anticoagulant from the peripheral vein of each patient and transferred to Department of Clinical Laboratory, which is a section of Fenghua Hospital of Traditional Chinese Medicine. Samples were centrifuged immediately for $15 \mathrm{~min}$ at $1000 \mathrm{~g}$. Then, plasma was collected and stored at $-80{ }^{\circ} \mathrm{C}$ before enzyme-linked immunosorbent assay (ELISA) measurement.

All individuals were informed of the purpose of the study and their informed consent was obtained. This study followed the tenets of the Declaration of Helsinki and was approved by the ethics committee of the institutional Fenghua Hospital of Traditional Chinese Medicine.

\section{Measurement of plasma Ephrin-A1 and VEGF 165}

Ephrin-A1 was measured using a commercial enzymelinked immunosorbent assay (ELISA) kit (LSBio, Seattle, WA, USA) and VEGF 165 was measured using a commercial enzyme-linked immunosorbent assay (ELISA) kit (R\&D systems, Minneapolis, MN, USA), following the instructions. Results were obtained by a multifunction microplate reader (Molecular Devices Inc., Sunnyvale, CA, USA). In addition, $6 \mathrm{ml}$ venous blood of subjects was taken for measurement of fasting blood glucose, HbA1c, serum creatinine, and total cholesterol levels.

\section{Statistical analysis}

Statistical analyses were performed using SPSS 18.0 (SPSS Inc. Chicago, IL, USA). The data were shown as mean \pm SD. After inspecting the distribution of the data, we assessed statistical significances with One-way ANOVA, 
Kruskal-Wallis Test, Mann-Whitney U Test corrected by Bonferroni. Correlations between any two of parameters including age, BMI, plasma ephrin- $\mathrm{A} 1, \mathrm{VEGF}_{165}$, fasting blood glucose levels, HbA1c, serum creatinine and total cholesterol were examined by Spearman's Correlation Analysis. Correlation between ephrin-A1 and duration of diabetes was performed by Pearson Correlation Analysis. $P<0.05$ was considered statistically significant.

\section{Results}

Clinical and laboratory data were shown in Table 1. There was no statistical difference in age, sex, $\mathrm{VEGF}_{165}$, serum creatinine and total cholesterol among the three groups of subjects. No relationship between Ephrin-A1 and $\mathrm{VEGF}_{165}$ in human plasma had been found. There were differences in fasting blood glucose and HbAlc among the three groups. Compared to the non-DM subjects, DM patients and DR patients had higher fasting blood glucose and HbA1c $(P<0.05)$.

Ephrin-A1 could be measured in human plasma, the averaged concentration of ephrin-A1 was $1.52 \pm 0.43$ (mean \pm SEM) $\mathrm{ng} / \mathrm{ml}$. The concentration of ephrin-A1 in the DR subjects was significantly higher than that of the other two groups $(P<0.05)$ (Fig. 1). This difference of the ephrin-A1 concentration was not found between the non-DM subjects and the DM subjects.

Plasma ephrin-A1 was correlated with the duration of diabetes $(r=0.513, P<0.05)$ and with Serum creatinine $(r=0.338, P<0.05)$, but was not correlated with age, BMI, serum $\mathrm{VEGF}_{165}$, total cholesterol, fasting blood glucose and HbA1c in the DR patients, the DM subjects, and the non-DM subjects or all subjects.

\section{Discussion}

Interaction between EphA receptor tyrosine kinases (RTKs) and ephrinA ligands is necessary for inducing of maximal neovascularization by VEGF [18]. EphA2 RTK is activated by VEGF through induction of ephrinA1 ligand [18]. Thus, we speculated that ephrin-A1 may be involved in the pathogenesis of DR and the ephrinA1concentrations in DR patients may be changed. To the best of our knowledge, no such research has been conducted before. Meanwhile, there were no reports about the association between ephrin-A1 and primary angle-closure suspects, or VEGF and primary angleclosure suspects in the literature.

In this study, ephrin-A1 concentrations in the plasma of non-diabetic, diabetic and DR patients were measured in a cohort of subjects. The averaged ephrin-A1 concentration in human plasma was $1.52 \pm 0.43$ (mean \pm SEM) $\mathrm{ng} / \mathrm{ml}$, indicating ephrin-A1 was expressed in human plasma. We found ephrin-A1 concentration in the DR group was higher than that in the non-diabetic and the diabetic groups, suggesting ephrin-A1 may be involved in the development of DR. There is evidence showed that ephrin-A1 inhibits VEGF-induced intracellular signaling and suppresses retinal neovascularization and blood-retinal barrier breakdown [19]. Previous studies reported that ephrin-A1 has also been shown to be expressed in the developing vasculature during embryogenesis [14] and in nenvascular cells during tumor growth [12]. However, where does the increased ephrin-A1 come from in diabetic retinopathy remains unknown, it may require further studies including multiple systems and organs.

We also measured the plasma concentrations of VEGF $_{165}$ in these patients. We did not find difference in

Table 1 Clinical and laboratory features of DR, DM and non-DM subjects

\begin{tabular}{|c|c|c|c|c|c|c|c|}
\hline & non-DM $(\boldsymbol{n}=19)$ & $\mathrm{DM}(\boldsymbol{n}=16)$ & $\mathrm{DR}(\boldsymbol{n}=20)$ & $P$ & $P$ Value 1 & $P$ Value 2 & $P$ Value 3 \\
\hline Age (years) & $60.53 \pm 4.04$ & $63.31 \pm 4.97$ & $60.25 \pm 6.72$ & 0.048 & 0.093 & 0.159 & 0.741 \\
\hline male/female & $11 / 8$ & $8 / 8$ & $11 / 9$ & & & & \\
\hline BMI (kg/m2) & $22.01 \pm 2.25$ & $24.48 \pm 3.17$ & $24.32 \pm 3.66$ & 0.032 & 0.068 & 1 & 0.072 \\
\hline $\mathrm{FPG}(\mathrm{mmol} / \mathrm{l})$ & $5.57 \pm 0.62$ & $8.91 \pm 3.04$ & $8.16 \pm 2.57$ & $<0.001$ & $<0.001$ & $>0.05$ & $<0.001$ \\
\hline $\mathrm{HbA1c}(\%)$ & $5.33 \pm 0.32$ & $8.65 \pm 2.56$ & $8.22 \pm 1.84$ & $<0.001$ & $<0.001$ & $>0.05$ & $<0.001$ \\
\hline VEGF165(pg/ml) & $34.79 \pm 38.65$ & $24.43 \pm 17.33$ & $40.91 \pm 58.01$ & 0.093 & & & \\
\hline Ephrin-A1(ng/ml) & $0.27 \pm 0.13$ & $0.35 \pm 0.34$ & $3.63 \pm 4.63$ & $<0.001$ & $>0.05$ & $<0.001$ & $<0.001$ \\
\hline Serum creatinine $(\mu \mathrm{g} / \mathrm{ml})$ & $54.32 \pm 12.74$ & $68.88 \pm 34.04$ & $70.10 \pm 26.63$ & 0.063 & & & \\
\hline Total cholesterol (mmol/l) & $5.19 \pm 1.09$ & $5.41 \pm 1.45$ & $5.00 \pm 1.00$ & 0.064 & & & \\
\hline Duration of DM (months) & 0 & $46 \pm 18.5$ & $118 \pm 49$ & & & & \\
\hline
\end{tabular}

$P$ indicates $P$ value of the three group; $P$ Value 1 indicates $P_{\text {adj }}$ value of the non-DM group vs the DM group; $P$ Value 2 indicates $P_{\text {adj }}$ value of the DM group vs the DR group; $P$ Value 3 indicates $P_{\text {adj }}$ value of the non-DM group vs the DR group.

BMI between the three groups was analyzed using one-way ANOVA. Age, HbA1c, FPG, serum creatinine, total cholesterol, ephrin-A1 and VEGF were analyzed by Kruskal-Wallis Test. The $P$ values of serum creatinine, total cholesterol and VEGF were $>0.05$, suggesting that there was no statistical significance between the three groups. We found that the $P$ values of age, HbA1c, fasting blood glucose and ephrin-A1 were $>0.05$, then Mann-Whitney $\mathrm{U}$ Test corrected by Bonferroni was further used for comparison between any two groups.

FPG Fasting plasma glucose. Values are means $\pm \mathrm{SD}$ 

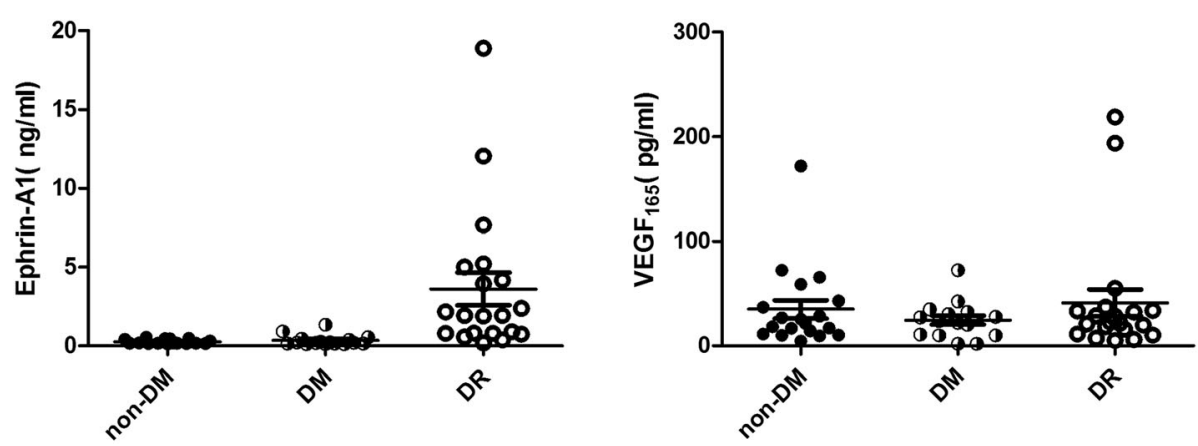

Fig. 1 Plasma VEGF 165 and Ephrin-A1 concentrations in DR and non-DR subjects. The concentration of ephrin-A1 of the DR subjects was significantly higher than that of the other two groups $(P<0.05)$. There was no statistical difference in VEGF 165 among the three groups

plasma VEGF $_{165}$ among the three groups. This result was inconsistent with a previous report that the plasma VEGF $_{165}$ concentration elevated in DR patients compared to non-DR controls [20]. Further studies are needed to confirm the changes of $\mathrm{VEGF}_{165}$ in the systemic circulation in DR patients.

\section{Conclusions}

This study is the first report that ephrin-A1 is presented in circulation. Furthermore, ephrin-A1 expression is elevated in DR patients, suggesting it may be involved in the pathogenesis of DR. Whether it may become a biomarker for the disease deserves further studies. Where does the increase ephrin-A1 come from and the mechanism of ephrin-A1 upregulation requires further research.

\section{Abbreviations}

VEGF: Endothelial-derived growth factor; DM: Diabetes; DR: Diabetic retinopathy; ELISA: Enzyme-linked immunosorbent assay;

EDTA: Ethylenediaminetetraacetic acid

\section{Acknowledgements}

We would like to thank all of the participants involved in this study.

\section{Authors' contributions}

YJ and BL conceived and designed the study. $\mathrm{YH}, \mathrm{QB}$ and KWW acquired the data. YDZ and YKY performed the study. DNM analyzed the data and wrote the manuscript. BL revised the manuscript critically. YJ and BL contributed to the manuscript as the corresponding author. All authors read and approved the final manuscript.

\section{Funding}

This work was supported by Fenghua District Science and Technology Bureau (20173604), partly providing fund to us for this study. They has no role in the design of the study and collection, analysis, and interpretation of data and in writing the manuscript.

\section{Availability of data and materials}

The datasets used and/or analyzed during the current study are available from the corresponding author on reasonable request.

\section{Ethics approval and consent to participate}

Ethics approval: This study was approved by institutional ethics committee in the Fenghua Hospital of Traditional Chinese Medicine. This study adhered to the tenets of the Declaration of Helsinki. Informed consents in written format to publish these data were collected from each patient, who agreed and signed the consent to participate statement.
Consent for publication

Not applicable.

\section{Competing interests}

The authors report no conflicts of interest.

\section{Author details}

${ }^{1}$ Department of Ophthalmology, Medical community of Fenghua Hospital of Traditional Chinese Medicine, 22 Zhong Shan Road, Feng Hua District, NingBo 315500, ZheJiang, China. ²Department of Clinical Laboratory, Medical community of Fenghua Hospital of Traditional Chinese Medicine, Ningbo, Zhejiang, China. ${ }^{3}$ People's Hospital of Zhengzhou University, Henan Provincial People's Hospital, Henan Eye Institute, Henan Eye Institute, 7\# Weiwu Road, Zhengzhou 450003, Henan, China.

Received: 30 April 2020 Accepted: 22 July 2020

Published online: 05 August 2020

References

1. Zheng $Y$, He M, Congdon N. The worldwide epidemic of diabetic retinopathy. Indian J Ophthalmol. 2012;60(5):428-31.

2. Sheetz MJ, King GL. Molecular understanding of hyperglycemia's adverse effects for diabetic complications. JAMA. 2002;288(20):2579-88.

3. Spranger J, Pfeiffer AF. New concepts in pathogenesis and treatment of diabetic retinopathy. Exp Clin Endocrinol Diabetes. 2001;109(Suppl 2): S438-50.

4. Gariano RF, Gardner TW. Retinal angiogenesis in development and disease. Nature. 2005;438(7070):960-6.

5. Robinson CJ, Stringer SE. The splice variants of vascular endothelial growth factor (VEGF) and their receptors. J Cell Sci. 2001;114(Pt 5):853-65.

6. Byrne AM, Bouchier-Hayes DJ, Harmey JH. Angiogenic and cell survival functions of vascular endothelial growth factor (VEGF). J Cell Mol Med. 2005; 9(4):777-94

7. Lu M, Kuroki M, Amano S, Tolentino M, Keough K, Kim I, et al. Advanced glycation end products increase retinal vascular endothelial growth factor expression. J Clin Invest. 1998;101(6):1219-24.

8. Petrovic MG, Korosec P, Kosnik M, Osredkar J, Hawlina M, Peterlin B, et al. Local and genetic determinants of vascular endothelial growth factor expression in advanced proliferative diabetic retinopathy. Mol Vis. 2008;14: 1382-7.

9. Zhou Q, Guo C, You A, Wang D, Wang W, Zhang X. One-year outcomes of novel VEGF decoy receptor therapy with intravitreal conbercept in diabetic retinopathy-induced macular edema. Mol Vis. 2019;25:636-44.

10. Gonzalez VH, Campbell J, Holekamp NM, Kiss S, Loewenstein A, Augustin AJ et al. Early and long-term responses to anti-vascular endothelial growth factor therapy in diabetic macular edema: analysis of protocol I data. Am J Ophthalmol. 2016;172:72-9.

11. Osaadon P, Fagan XJ, Lifshitz T, Levy J. A review of anti-VEGF agents for proliferative diabetic retinopathy. Eye. 2014;28(5):510-20. 
12. McBride $\mathrm{JL}$, Ruiz JC. Ephrin-A1 is expressed at sites of vascular development in the mouse. Mech Dev. 1998;77(2):201-4. https://doi.org/10.1016/s09254773(98)00142-7.

13. Pandey A, Lazar DF, Saltiel AR, Dixit VM. Activation of the Eck receptor protein tyrosine kinase stimulates phosphatidylinositol 3-kinase activity. J Biol Chem. 1994;269(48):30154-7.

14. Ogawa K, Pasqualini R, Lindberg RA, Kain R, Freeman AL, Pasquale EB. The ephrin-A1 ligand and its receptor, EphA2, are expressed during tumor neovascularization. Oncogene. 2000;19(52):6043-52.

15. Foster PJ, Buhrmann R, Quigley HA, Johnson GJ. The definition and classification of glaucoma in prevalence surveys. Br J Ophthalmol. 2002; 86(2):238-42. https://doi.org/10.1136/bjo.86.2.238.

16. American Diabetes A. Standards of medical Care in Diabetes-2018 abridged for primary care providers. Clin Diabetes. 2018;36(1):14-37.

17. Watkins PJ. Retinopathy. BMJ. 2003:326(7395):924-6.

18. Cheng N, Brantley DM, Liu H, Lin Q, Enriquez M, Gale N, et al. Blockade of EphA receptor tyrosine kinase activation inhibits vascular endothelial cell growth factor-induced angiogenesis. Mol Cancer Res. 2002;1(1):2-11.

19. Ojima T, Takagi H, Suzuma K, et al. EphrinA1 inhibits vascular endothelial growth factor-induced intracellular signaling and suppresses retinal neovascularization and blood-retinal barrier breakdown. Am J Pathol. 2006; 168(1):331-9. https://doi.org/10.2353/ajpath.2006.050435.

20. Paine SK, Mondal LK, Borah PK, Bhattacharya CK, Mahanta J. Pro- and antiangiogenic VEGF and its receptor status for the severity of diabetic retinopathy. Mol Vis. 2017;23:356-63.

\section{Publisher's Note}

Springer Nature remains neutral with regard to jurisdictional claims in published maps and institutional affiliations.

Ready to submit your research? Choose BMC and benefit from:

- fast, convenient online submission

- thorough peer review by experienced researchers in your field

- rapid publication on acceptance

- support for research data, including large and complex data types

- gold Open Access which fosters wider collaboration and increased citations

- maximum visibility for your research: over $100 \mathrm{M}$ website views per year

At $\mathrm{BMC}$, research is always in progress.

Learn more biomedcentral.com/submissions 